\title{
Effects of Computerized Emotional Training on Children with High Functioning Autism
}

\author{
Stefano Piana, Chiara Malagoli, Maria Carmen Usai, and Antonio Camurri
}

\begin{abstract}
An evaluation study of a serious game and a system for the automatic emotion recognition designed for helping autistic children to learn to recognize and express emotions by means of their full-body movement is presented. Three-dimensional motion data of full-body movements are obtained from RGB-D sensors and used to recognize emotions by means of linear SVMs. Ten children diagnosed with High Functioning Autism or Asperger Syndrome were involved in the evaluation phase, consisting of repeated sessions to play a specifically designed serious game. Results from the evaluation study show an increase of tasks accuracy from the beginning to the end of training sessions in the trained group. In particular, while the increase of recognition accuracy was concentrated in the first sessions of the game, the increase for expression accuracy is more gradual throughout all sessions. Moreover, the training seems to produce a transfer effect on facial expression recognition.
\end{abstract}

Index Terms-Emotion Recognition, Full-Body Movement, Evaluation, Serious Game, Autism Spectrum Condition.

\section{INTRODUCTION}

A UTISTIC spectrum conditions (ASC), also known as Autistic spectrum disorders (ASD), are characterized by difficulties in the social \& communication domain, next to the presence of restricted repetitive behaviours [1]. Classic literature recognized deficits in the domains of affective relationships and emotional behaviour as other aspects of ASC [2]. Failures in interpersonal exchanges have been thought as a consequence to impairments in understanding others intentions, thoughts, and emotions [3]. In particular literature shows that children and adults with ASC display deficits in emotion recognition [4], [5], [6], [7], [8] limiting their social integration and interaction with other people. Given this background, this study aims to investigate the efficacy of a serious game in promoting emotional competence in children with ASC.

\subsection{Development of emotions in TD and ASC children}

The ability to discriminate a limited set of primary emotions appears early so that three months old typical developing (TD) children are able to distinguish happy from sad and surprised static faces [9] as well as by seven months they are able to differentiate happy from angry faces when presented in a dynamic fashion [10]. Despite the differences due to the task employed and to the specific emotion examined, the ability to identify prototypical emotional expressions generally improves with age and reaches maturity by 10 years of age [11], [12], even though difficulties in recognizing less intense emotions may persist until adolescence [13], [14]. Considering the emotion processing in ASC population,

- S. Piana and A. Camurri are with the Department of Informatics, Bioengineering, Robotics and System Engineering, University of Genoa, Genoa, Italy.

E-mail: stefano.piana@unige.edu, antonio.camurri@unige.it

- C. Malagoli and M. C. Usai are with the Department of Education Science, University of Genoa, Genoa, Italy.

E-mail: chiara.malagoli@edu.unige.it, maria.carmen.usai@unige.it

Manuscript received Month DD, YYYY; revised Month DD, YYYY. literature disagrees about the presence of impairments in perception of emotion competence. Three recent reviews show an inconsistent pattern of results about individuals with ASC [15], [16], [17]: a small but significant effect indicates that individuals with ASC show a poorer face perception of emotion compared to typically developing groups [17], but considering children, no difference between groups were found in basic emotion perception skills, when other variables such as intellectual disability are taken into account. Nuskhe et al. [16] showed that the impairment in emotion processing is not homogeneously distributed in ASC samples, and depends on participant characteristics and on emotion testing procedures. More recently Peterson et al. [18] compared the ability to recognize emotions in the body postures ("body-reading") with the ability to recognize emotions expressed by the eyes ("eye-reading") in children with and without ASC, controlling for other conditions that were sources of limitation in past studies: the results indicate that children with ASC did not differ from the age-matched TD control in recognizing emotions expressed through body postures, despite having lower scores in verbal IQ; moreover, children with ASC performed poorer with the same emotions by eye-reading. These results show that the ASC impairment in decoding others basic emotions depends also on the modality used to assess the emotion competence. Although emotions can be expressed through different modalities, the literature mainly focused on facial expressions recognition. Therefore, the study of body and gestures expressions may be important as well because in everyday interaction people rely on both facial and bodily communication [19], [20], [21]. Moreover different non-verbal channels are used to communicate predominantly some emotions: intimate and survival emotions are supported primarily by the face and the touch channel, whereas the body channel conveys social-status emotions [22]. Similar to facial expressions, bodily expressions are easily recognized [23], [24], [25], moreover emotions can be distinguished using only biological motion [23], [26] also in 
a situation of social interaction [27]. Few studies consider the individual sensitivity to emotions conveyed by body postures. Studies on the TD population showed that adults make errors in identifying the six basic emotions through a number of static whole of body pictures [28]: error rate ranged from $22 \%$ for postures referred to the disgust, $20 \%$ and $16 \%$ respectively, in case of anger or fear poses. As suggested by Peterson et al. [18], individuals with ASC, given their reluctance to make eye contact and to confront faces at close range [29] may show fewer difficulties in reading emotion in body language than in reading facial expressions. Indeed their results suggest that body language is more effective and might constitute a more congenial medium for accessing others' emotions. As suggested by Reed et al. [30], individuals with ASC may benefit from intervention based on understanding body movements.

\subsection{Related work}

In this paper we propose the evaluation of a system designed to recognize emotional states from body motion and gestures [31], [32], [33]. The system is based on experimental psychology studies [34], [35], [36], [37], [38] and humanistic theories [39], [40] where authors present how the body movements are related to emotions. Literature shows great efforts to teach emotional competence to individuals with ASC, but reviews on computer-based interventions show that the efficacy of such systems is often not substantial [41]; moreover, the interventions have addressed a range of social and emotional behaviours but, to our knowledge, they did not train the ability to recognize and express emotion by body movement. This work was inspired by previous research on automatic emotion recognition: Kapur et al. [37] showed how four basic emotions could be automatically distinguished from simple statistical measures of motion's dynamics. Balomenos et al. [42] combined facial expressions and hand gestures for the recognition of six prototypical emotions. In the last years, different approaches emerged to help ASC affected subjects in improving their social integration: numerous serious games were developed to help children improve social interaction and conversations skills [43], [44], [45] or improve speech [46], [47] and help them in daily life situations [48], [49]. Most of the works on emotional training focused on speech [46], [50] or face expressions [51], [52] and most of the games use classic interaction paradigms. Robin and colleagues [53], showed that a robot assistant could help in improving social interaction in ASC children. Robots were employed also by Wainer and colleagues [54] and Dautenhahn and Billard [55]. This work focuses on training body language and includes both recognition and expression of emotions through gestures in a serious game for emotional training of ASC-affected children. The interaction with the system through body gestures is performed employing low-cost motion capture devices (RGB-D cameras [56]), that are less precise than professional-grade motion capture systems, but easier to install and adopt in daily-use scenarios: this enabled us to design serious games with the ability to analyse children movements and infer the expressed emotion from body gestures. This work originated from the European Project FP7 ICT ASC-Inclusion [57], [58]. The paper is organized

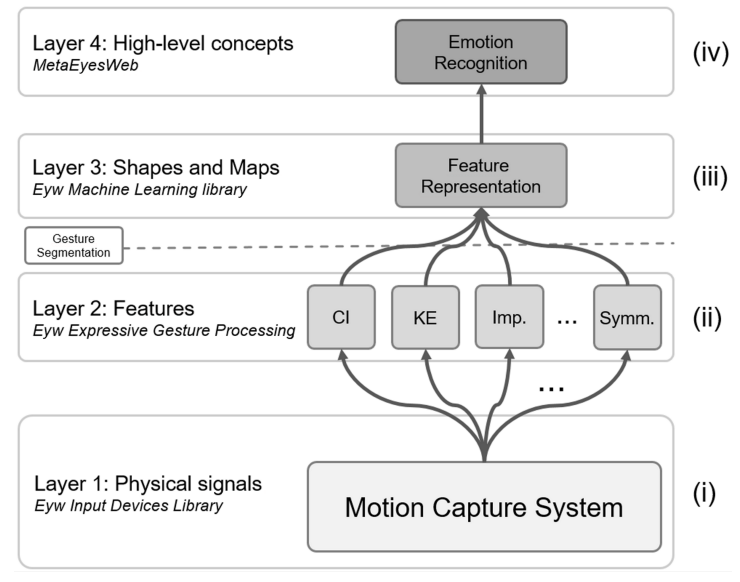

Fig. 1. The proposed Conceptual Framework, derived from [60]: Motion Capture input data are processed to extract movement features (Layer 2 ), then a statistical representation of such features is built (Layer 3); finally, a classifier (Layer 4) is adopted for the final emotion recognition.

as follows: first a brief description of the conceptual frameworks for movement analysis and of the designed recognition system are given, then the design of the serious game and the evaluation method are presented; finally results of the evaluation and a discussion are proposed.

\section{Conceptual fRAmework AND System De- SIGN}

This section introduces the developed emotion recognition system to infer emotions from body gestures and the serious game, that we evaluated with a small population of autistic children. In this work, we will focus on the recognition and expression of 4 basic [59] emotions conveyed through body gestures: Happiness, Sadness, Anger and Fear.

\subsection{System Framework and Design}

The presented system is inspired by the multi-layered conceptual framework for non-verbal multi-modal interaction presented by Camurri et al. in [35], [60] and further refined in [61]. The framework focuses on the definition of a set of movement features and algorithms to compute them. The features are organized in a layered way: physical-level (e.g., velocity, acceleration), low-level (e.g. symmetry, smoothness), and mid-level (e.g., fluidity).

As discussed in [61], the mid-level is of particular importance: for example, the fluidity of a body movement is a higher-level quality with respect to smoothness [62]: to obtain fluidity, joint movements must be smooth and coordinated, like in a "wave" propagation effect of the energy along the body. from these premises, and from the results obtained by the optimization of the feature set to the proposed machine learning model [33], we converged to the movement features summarized in Table 1. Figure 1 shows the system architecture: first (i) the system performs the synchronization of different input streams received from sensors, then (ii) extracts and analyses a set of movement features, generates (iii) a statistical representation of the extracted information and finally (iv) performs the analysis of such data to infer the user's emotional state. 
The system is based on the EyesWeb XMI ${ }^{1}$ software platform [63], [64], [65]. EyesWeb XMI is a modular distributed development environment that supports the design and implementation of interactive systems and applications. Each specific task is carried out by an Eyesweb XMI Application (Patch). A Patch is a graph of linked modules (Blocks), where each Block performs a single operation (e.g., capture images from a camera, apply specific machine learning techniques on time series). Linking different Blocks together allow to easily and quickly build systems to solve various and complex problems. The EyesWeb XMI Environment supports multimodal processing, by managing the realtime acquisition, synchronization, and analysis of signals from various input devices such as webcams, microphones, Motion Capture, and physiological sensors. We used the input Devices Library (shown in the bottom layer of Figure 1 ), to capture and perform early processing on the input streams (e.g., images, motion capture data) coming from a Kinect2 Sensor.

\section{On-line feature extraction}

To compute features on the received data streams EyesWeb XMI provides a vast library of modules for expressive gesture analysis and machine learning [60], which has been updated and extended to extract the movement features. Table 1 lists the feature considered in this work, detailed algorithms for the feature extraction are described in [33].

The features considered in this work include: kinematics on single joints (i.e., velocities, accelerations) computed at high sample rates; mid-level features that consider groups of joints (i.e., spatial occupation, postural attitudes), and complex quantities computed on the whole body of the participant (i.e., movement fluidity, periodicity, symmetries) that requires longer observation periods. A detailed description of the features analysed in real-time by our serious game is presented in [33].

\section{Emotion inference}

As depicted in Figure 1, Physical Signals (i) and Features (ii) are used to model mid-level features in terms of Shapes and Maps in feature spaces (iii): in our system during this phase histograms and adaptive descriptors are computed from the available features. Histogram representations are calculated by EyesWeb machine learning library. In order to learn the adaptive representations we use EyesWeb and PADDLE [66]. The High-level concepts layer (iv), in our application, concerns the understanding of users emotional states based on the previously described models. This task is performed using SVM models trained on a corpus recorded with the participation of Typically Developing children [33]. Figure 2 depicts a detailed view of the designed system. A Blocks diagram is shown, where each block represents a module of the application, and the respective layer of the conceptual framework. Each module is implemented as an EyesWeb Patch with a specific purpose: capturing data from the sensors and tracking the user, performing feature extraction and computing the data representation, logging sensor's data and usage statistics to file, generating the user interface and controlling the evolution of the serious

1. http://www.infomus.org/eyesweb_eng.php
TABLE 1

The list of movement features considered in this work. These factors comprehend simple kinematics (i.e., velocities, accelerations) of single joints, spatial occupation-related features computed on group of joints, and more complex features (i.e., movement fluidity, periodicity, symmetries) computed on the whole body.

\begin{tabular}{lll}
\hline Feature & Type & Relative joint(s) \\
\hline Kinetic energy & $\begin{array}{l}\text { Holistic, } \\
\text { Kinematic }\end{array}$ & All \\
\hline Contraction index & $\begin{array}{l}\text { Holistic, } \\
\text { Postural }\end{array}$ & All \\
\hline Symmetry & $\begin{array}{l}\text { Holistic, } \\
\text { Postural }\end{array}$ & All \\
\hline Postural Attitudes & $\begin{array}{l}\text { Holistic and local, } \\
\text { Postural }\end{array}$ & $\begin{array}{l}\text { Trunks joints, } \\
\text { head }\end{array}$ \\
\hline Periodicity & $\begin{array}{l}\text { Holistic and local, } \\
\text { Postural }\end{array}$ & $\begin{array}{l}\text { All, shoulders, } \\
\text { hands }\end{array}$ \\
\hline Direction of movement & $\begin{array}{l}\text { Holistic and local, } \\
\text { Postural }\end{array}$ & $\begin{array}{l}\text { All, hands, } \\
\text { elbows }\end{array}$ \\
\hline Kinematics & $\begin{array}{l}\text { Local, } \\
\text { Kinematic }\end{array}$ & $\begin{array}{l}\text { Hands, elbows, } \\
\text { shoulders }\end{array}$ \\
\hline Fluidity & $\begin{array}{l}\text { Holistic, } \\
\text { Kinematic }\end{array}$ & All \\
\hline Impulsiveness & $\begin{array}{l}\text { Local, } \\
\text { Kinematic }\end{array}$ & $\begin{array}{l}\text { Local, } \\
\text { Trajectory }\end{array}$ \\
\hline Local, \\
Trajectory
\end{tabular}

games, performing the classification and emotion inference. Figure 2 shows how the data is flowing through the various modules: raw video streams are captured from the input device, a Kinect v2 sensor, and used to extract motion capture data (i), this data is saved to file for further offline analysis and sent to the feature extraction module (ii) where movement features are extracted and used to build a statistical representation of the performed movement (iii) that is finally used to infer the child's emotional state in the emotion classification module (iv). Results of the emotion classification are then presented to the child via the user interface, that will be described in the next section.

\subsection{Serious Game}

The system architecture described above has been successfully applied in the design of a serious game to help autistic children in learning to recognize and to express emotions through full-body movement. As mentioned above, our goal was to develop an emotion recognition module and 


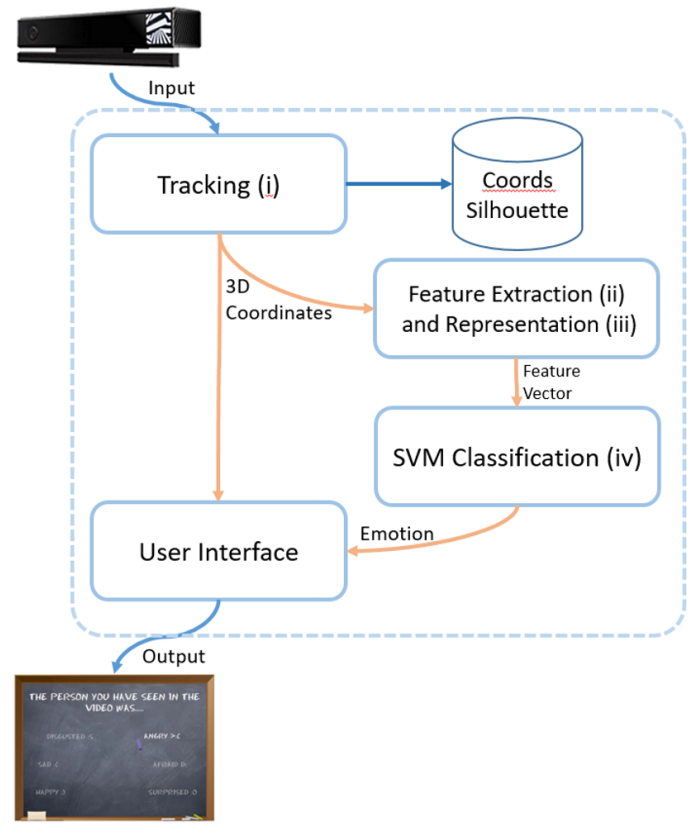

Fig. 2. The diagram shows the data flow in the system. Image streams from input devices (i.e., Kinect) are processed to get motion capture data, logs data to file and send them to the other components; the Feature extractor, computes expressive features, generates feature vectors and sends them to the classifier, that, given the feature vector produces classification results. The user interface controls and monitors the interaction with users, synchronizes all the other components, receives $3 d$ coordinates and images from the tracker, inferred emotions from the classifier, and produces outputs (i.e., audiovisual output).

to integrate it into a serious game, to teach children with Autism Spectrum Condition how they can improve their context-dependent body emotional expressiveness.

\section{Design Phase}

During the development of the system, several TD children aged 8-11 were contacted and involved in an iterative design phase and 42 children participated in the process. Early installations of the serious game platform were installed in schools to evaluate the design of the game and to capture new data to improve the interaction design and the emotion recognition models.

The very first iteration of the game was represented just by a series of screens that asked the participant to recognize, and then express, an emotion presented by a set of randomly selected videos showing black and white silhouettes of people expressing one of the basic emotions. At this stage the recognition system was not present and the recognition of the emotion expressed by the child was performed by one human operator. During the design phase we tried to keep the interaction with the game prototypes as simple and engaging as possible; to this aim we devised a minimal graphical user interface based on the metaphor of an active school blackboard. All the contents of the games are presented as written on a blackboard, Figure 3 depicts how the interface appears to the child. The child can interact with the games through gestures: raising a hand will activate a cursor, presented as a piece of chalk that can be moved on screen simply by moving the hand; the interface presents active zones that trigger the progression

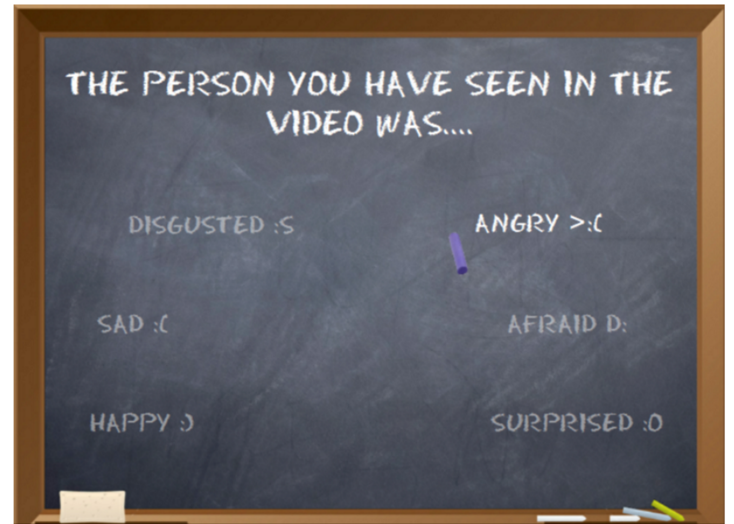

Fig. 3. The user interface of the designed games, all the content is presented on a blackboard and the user interacts using gestures, the Figure shows a screen where the player is asked to select one of the six basic emotions by dragging the piece of chalk (cursor) on one of the proposed emotions.

of the game. These zones can be activated by dragging the cursor on them and keeping it on the active zone for a brief period of time.

Basing on this simple interaction design we developed a game prototype that performs real-time automatic emotion recognition using the system introduced earlier and described in details in [33], and interacts with the child by asking to guess an emotion, and to express it with her body. Children interact with the game through body gesture and, depending on the turn, they have to guess an emotion or perform it with the body.

\subsubsection{The Serious Game "Guess the Emotion"}

Guess The Emotion (Figure 3) is a simple single-player game that is composed of two phases. At first, the system shows to the player a short video of a person that expresses an emotion. So as to help to focus just on the information carried by the body movements and discard other stimuli (context, facial expression, voice) a black and white silhouette of a child is shown. The player is then asked to pick from a list the emotion that in his or her opinion the person in the video was feeling (before answering, the player may also ask the system to see again the video, in case of doubt). If the player's answer is correct he or she gains one point. Then the game asks the player to express the same emotion of the video with his or her own body. While the player tries to express the emotion, the recognizing system will try to understand which emotion is being expressed by the player. If the recognized emotion matches the required one the player gains a point, if it is different from the correct one the system will ask the player if he or she wants to try again. In general, the system, when unsure what to answer about an emotion, never states that the child expression was wrong but apologizes for not being able to recognize the right emotion and encourages the child to repeat the expression task. The player has up to three attempts. In case of success or when all attempts are used, the game ends and the final score is given, which includes the points acquired during the two phases of the game. 
TABLE 2

Data of the participants in the evaluation phase, thirteen families were contacted, after a first evaluation ten children were selected to participate in the evaluation

\begin{tabular}{|c|l|l|l|l|l|}
\hline ID & Gender & Age & Diagnosis & IQ & IQ Test \\
\hline 2 & $\mathrm{M}$ & 8 & $\begin{array}{l}\text { Asperger } \\
\text { Syndrome }\end{array}$ & 103 & WISC-III \\
\hline 3 & $\mathrm{M}$ & 8 & $\begin{array}{l}\text { Asperger } \\
\text { Syndrome }\end{array}$ & 97 & WISC-III \\
\hline 4 & $\mathrm{M}$ & 9 & PDD-NAS HFA & 91 & LEITER \\
\hline 5 & $\mathrm{M}$ & 10 & PDD-NAS HFA & 91 & LEITER \\
\hline 6 & $\mathrm{M}$ & 9 & $\begin{array}{l}\text { Asperger } \\
\text { Syndrome }\end{array}$ & 74 & LEITER \\
\hline 8 & $\mathrm{M}$ & 8 & $\begin{array}{l}\text { Asperger } \\
\text { Syndrome }\end{array}$ & 70 & LEITER \\
\hline 10 & $\mathrm{M}$ & 11 & $\begin{array}{l}\text { Asperger } \\
\text { Syndrome }\end{array}$ & 76 & LEITER \\
\hline 11 & $\mathrm{M}$ & 11 & PDD-NAS HFA & 70 & LEITER \\
\hline 12 & $\mathrm{M}$ & 10 & $\begin{array}{l}\text { Asperger } \\
\text { Syndrome }\end{array}$ & 91 & LEITER \\
\hline 13 & $\mathrm{~F}$ & 9 & $\begin{array}{l}\text { Asperger } \\
\text { Syndrome }\end{array}$ & 109 & WISC-IV \\
\hline
\end{tabular}

\section{EVALUATION PROCEDURE}

To evaluate the serious game and its effectiveness in teaching emotions to ASC children, we designed a training program for children with ASC. Thanks to three local treatment centres (Istituto Chiossone [67], Mai Soli [68] and Philos [69]) thirteen families were contacted to participate in the evaluation of the developed recognition system and serious game. After a first preliminary evaluation, due to unavailability to participate in all the training sessions or non-satisfaction of the requirements, three children were excluded from the final evaluation process. Finally, ten children diagnosed with High Functioning Autism or Asperger Syndrome (mean IQ 87.2, mean age 9.6 years old, 9 boys and 1 girl) were included in the evaluation. Table 2 shows some information about the participants.

\section{Participants}

The families were contacted through the involved treatment centres. The inclusion criterion was a diagnosis of highfunctioning autism; Autistic children diagnosed also with other genetic syndromes or other developmental disorders were not selected to participate. In addition, all selected children had adequate verbal skills to enable them to carry out the training activities. Informed consent for the participation in the experiment and acquisition of medical information about the children was signed by the parents. Recent information about IQ was requested. The brief IQ from Leiter scale [70] was administered in the case that the IQ information was not available. Participating children were asked to take part in a training activity during which they played several times with the Guess the emotion serious

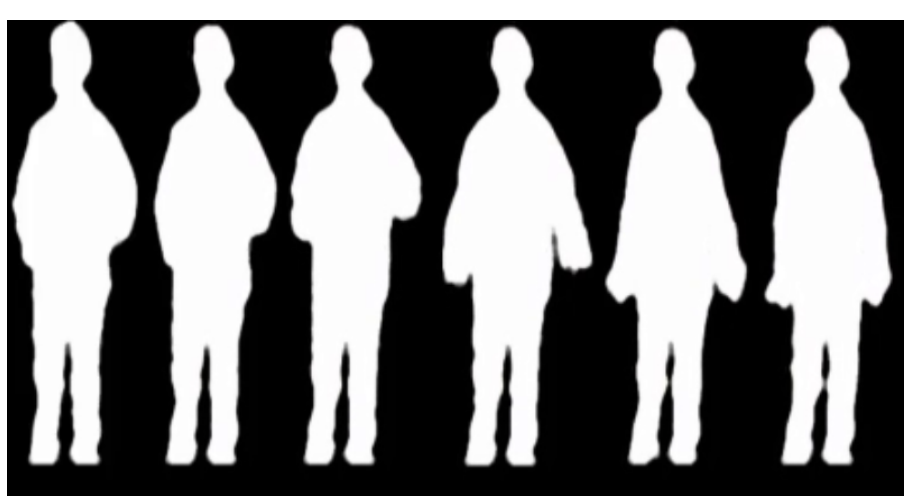

Fig. 4. A Sequence of images representing a video presented during the recognition phase in the Guess the emotion serious game: the child is, in this case, expressing anger, represented by sudden and tense movements of the arms towards the floor.

game. Each participant was assessed before and after the training program. The assessment included:

- Leiter Scale IQ test [70] (if the IQ was not already available).

- The Italian version of Test of Emotions Comprehension by Harris, Pons \& De Rosnay [38].

The administration of the tests gave the opportunity to proceed with the experiment and compare the results of the participant with a standard population.

\section{Ethical Standards}

A letter with the presentation of the project was given to the parents; the letter contained the name of the project responsible and of a contact person and their contact details; for each child an informed consent to participation was required; Meetings were organized to inform parents on the objectives and methods of the study. Skilled and experienced personnel was employed in the evaluation of children and in the administration of the training.

\section{Training Procedure}

The training protocol consisted of ten sessions where children were asked to play the Guess the Emotion serious game, each session lasting a maximum of twenty minutes. Children participated with a frequency of two to three sessions a week in the treatment centre attended by the child for rehabilitation, the total duration of the training program was about 4 to 6 weeks, according to children and treatment centers availability. Each game session was divided into two phases. During the first phase (Recognition Task) a black and white video of Typically developed children was shown. The video consisted of the silhouette of a child expressing one of the basic emotions. We chose to show just the silhouette in order to better focus on body language. Once the video is shown the participant is asked to guess which emotion was expressed in the shown video. The game then moves to the Expression Task where the child has to express the emotion that was presented in the video using his own body gestures, the movements of the child are analyzed as described in Section 2.2. At the beginning of the training, the children were told that, if they were mistaken in playing the game, they may repeat the failed trial. If 

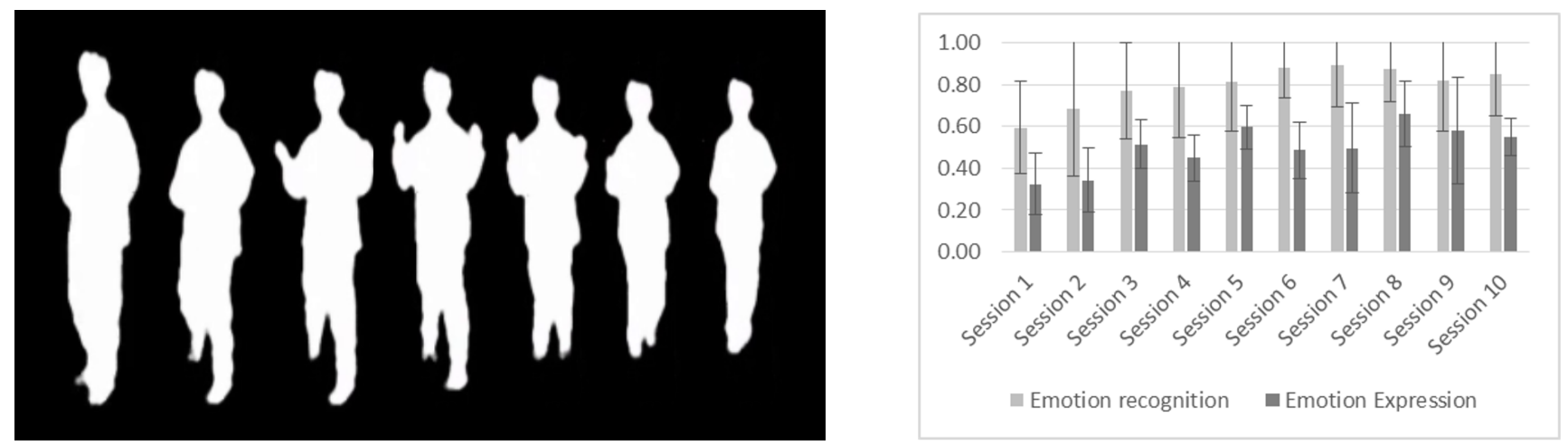

Fig. 5. A Sequence of images representing a video presented during the recognition phase in the Guess the emotion serious game: the child is, in this case, expressing fear, represented by sudden backward movements and quick movements with the arms to protect themselves. A video showing a few sessions with the serious game is available at https://www.youtube.com/watch?v=42sByh2zkL8list =PLEVgkiAQI8zJvou8mM8alLpATh9ZL793x

they managed to perform correctly, the game would proceed without asking them to repeat the trial. A complete training session lasting at maximum twenty minutes consisted of twelve rounds of the serious game, each round consisting of a recognition and an expression phase. the proposed emotions were selected in a pseudo-random way in order to present each emotion three times for each complete training and avoid any memorization of the proposed emotions for subsequent training sessions.

The videos used in the recognition phase were rated by 40 anonymous adults, in order to have good stimuli, we selected videos reaching an agreement between raters greater than $80 \%$ (inter-raters consistency). A total of 36 videos were selected to be included as stimuli. Once the stimuli are presented, the participant is asked to recognize which emotion is expressed in the video; we selected multiple stimuli for each emotion, to propose different videos each time and avoid biases due to participant learning to associate the video to a certain emotion. Figures 4 and 5 show two examples of stimuli we used during the training. Figure 4 shows a silhouette of a child expressing anger characterized by sudden and tense movements of the arms towards the floor, Figure 5 shows a sequence portraying fear, where the movements are characterized by sudden movements backward and a movement of the arms to protect themselves.

During the training the children body movement and their interaction with the serious game (i.e., in-game children's answers during the first phase, inferences of the recognition system and number of trials during the second phase) was recorded. This made possible the analysis of participants movement and the observation of the evolution of his or her performances as they performed training.

\section{RESULTS}

Considering the results obtained by the children in the overall sessions of the serious game, they do not show a significant difference between recognition and expression in the mean gains obtained by subtracting the accuracy score between couples of two subsequent sessions (accuracy on
Fig. 6. Evolution of the mean ratios of correct answers given respectively by the children during the recognition task in the game (light grey) and by the system during the expression task.

the second minus accuracy on the first, accuracy on the third minus accuracy on the second, and so on), respectively Mean RecognitionGain $=0.28$, st.dev. $=0.14$, and Mean $_{\text {ExpressionGain }}=0.21$, st.dev. $=0.11$.

Considering the performance in the serious game session by session, Figure 6 shows the mean accuracy in the recognition task (light grey bars) and in the expression during the second task (dark grey bars). Both indexes tend to grow across the various sessions, the recognition accuracy seems to grow during the first sessions and reach a regime value that is maintained in the last sessions. The expression accuracy shows a different trend showing a certain variability across sessions. To better analyse the effects of the serious game from the early to the later sessions, we compare the mean accuracy between two periods, the first six sessions being the first period and the last four being the second one. Considering that ASC individuals need of larger time to adapt their-selves to new tasks and situations, we included in the first period more sessions than in the second. Looking at the mean accuracy between the first period and the second period separately for each task, a significant difference was found both for the recognition, $t(9)=3.984, p=0.003$ and the expression task, $t(9)=$ $4.439, p=0.002$, indicating that the performance at this task increase significantly from the first to the second period. Comparing now the mean gains between tasks separately for the two periods, in the first period gains obtained by the children in the recognition task are higher than those in the expression task, $t(9)=2.594, p=0.029$ (Figure 8), while the performance between the two tasks do not differ significantly in the second period. In order to check for bias due to the sessions selection we re-run the analyses with different groups of sessions. Considering the first period as composed by different sessions (1-6, 1-7, or 1-8) and the second period as composed by the remaining sessions (7$10,8-10$, or 9-10), there is always a significant increase of accuracy for both recognition and expression (see the table below). Figure 6 shows that the accuracy in the recognition and in the expression tasks increase at a different rate. While the increase of recognition accuracy was concentrated in the first six sessions of game, the increase for expression accuracy is more gradual.

As regards the performance of children with ASC on 
TABLE 3

Between emotion comparison: the statistics show no differences among the four emotions in the recognition task $(F=2.782, p=.120)$ but show significant differences among the emotions in the expression task $(F=109.486, p<.001)$.

\begin{tabular}{llllll}
\hline Task & Emotion & Mean & St. dev. & Min & Max \\
\hline \multirow{2}{*}{ Recognition } & Sadness & 0.765 & 0.169 & 0.435 & 0.950 \\
& Anger & 0.870 & 0.187 & 0.381 & 1.000 \\
& Happiness & 0.863 & 0.206 & 0.300 & 1.000 \\
& Fear & 0.760 & 0.182 & 0.421 & 1.000 \\
\hline \multirow{7}{*}{ Expression } & Sadness & 0.631 & 0.187 & 0.250 & 0.818 \\
& Anger & 0.445 & 0.242 & 0.143 & 0.789 \\
& Happiness & 0.742 & 0.133 & 0.435 & 0.947 \\
& Fear & 0.083 & 0.071 & 0 & 0.200 \\
\hline
\end{tabular}

the specific emotions, as shown in Table 3, there were no significant differences among the four emotions in the recognition task $(F=2.782, p=.120)$. Differently, children showed significant differences among the emotions in the expression task $(F=109.486, p<.001)$. In particular, they struggled more when they were asked to express fear than in the case of the other three emotions (in post-hoc all $p s<.01)$. The difficulties showed by the children with ASD in reproducing fear body movements must be discussed, because this result appears in contrast with some studies including children with high-functioning ASD that reported relatively intact expression of emotions in response to a negative stimulus [71], [72]. Considering that in the present study children had to reproduce the behavioural features of the fear in the absence of a spontaneous emotional status, an explanation may call into account the imitation deficits in ASD observed in many studies (see e.g., [73]).

To verify whether the increase of performance in the game corresponds to a generalized increase of ability to recognize the emotions by the facial expressions, a comparison between pre- and post-training performance at TEC test was conducted. Table 4 shows the number of correct answers, the correspondent score, and the centiles for each child at the TEC test. The repeated measure ANOVA shows that centiles at the post-test are significantly higher than centiles at the pre-test, $F(1,9)=6.048, p=0.036, \eta_{p}^{2}=0.402$ (Figure $7)$. We also calculated the U3 statistic that is a measure of overlap that refers to the percentage of scores in a group that is exceeded by the average score for another group [74]. The U3 shows that $70 \%$ of children increase the number of correct answer after the training. The same tendency is observable centiles $(60 \%)$.

Figure 7 shows the mean gains of the group of participants in the percentiles in the TEC test. These results evidence a general increase of the accuracy in emotion recognition measured with TEC in the post-test phase. A comparison of the gains in the TEC test and in-game tasks results on the whole training period evidenced an overall correlation (Spearman [75]) between the Expression in-game task and the TEC scores $(p<0.05)$, while no significant correlation between the Recognition task and the scores was found: this may be due to a saturation effect in the recognition task scores (visible in Figure 6).
TABLE 4

Correct answers, TEC scores and centiles at the evaluation TEC test; pre-training and post-training scores are reported, the highlighted rows represent subjects of which scores got better after the training (light grey) or whose scores got worse than in the pre-training test (dark grey).

\begin{tabular}{|c|c|c|c|c|c|c|}
\hline & \multicolumn{3}{|c|}{ Pre-Training } & \multicolumn{3}{c|}{ Post-Training } \\
\hline ID & $\begin{array}{c}\text { Correct } \\
\text { Answers }\end{array}$ & $\begin{array}{c}\text { TEC } \\
\text { pts }\end{array}$ & Centiles & $\begin{array}{c}\text { Correct } \\
\text { Answers }\end{array}$ & $\begin{array}{c}\text { TEC } \\
\text { pts }\end{array}$ & Centiles \\
\hline 2 & 26 & 8 & 54 & 28 & 9 & 85 \\
3 & 25 & 7 & 26 & 27 & 8 & 54 \\
4 & 28 & 8 & 46 & 2 & 8 & 46 \\
5 & 26 & 7 & 23 & 23 & 5 & 3 \\
6 & 21 & 4 & 1 & 21 & 4 & 1 \\
8 & 23 & 5 & 9 & 23 & 6 & 21 \\
10 & 23 & 4 & 1 & 29 & 9 & 82 \\
11 & 28 & 8 & 43 & 29 & 9 & 82 \\
12 & 26 & 6 & 10 & 26 & 7 & 23 \\
13 & 27 & 8 & 54 & 28 & 9 & 85 \\
\hline Mean & 25.30 & 6.50 & 26.70 & 26.20 & 7.40 & 48.20 \\
\hline
\end{tabular}

Considering now the correlations relative to the two separate periods of training, the percentile gains in TEC test is significantly correlated $(p<0.05)$ with the mean score in the Expression task relative to the second period (See Table 5). It is worth noting that the TEC test is a general test on emotion recognition, while the proposed training program focused on body gestures only, thus the improvement in the TEC scores seem to suggest that the children were able to generalize from a much-focused task to a more general one.

A pilot study was realized to compare the TEC test change in a control group. The control group was recruited through several treatment centres. The inclusion criteria are the same as for the experimental group. The family of five children (mean IQ 92.2, st. dev. 17.14; mean age 9.8 years, st. dev. $0.45 ; 4$ males and 1 girl) accepted to participate. The control group was assessed with the TEC test two times with an interval of about two months between the two assessments as the experimental group did. Analyses do not reveal any significant difference between the experimental and the control group, nevertheless, as can be observed in table 6 that shows the control group result, the mean difference between the first and the second assessment percentiles in TEC test was lower in the control group (9.60) than in the experimental group (21.50).

\section{CONCLUSION AND DISCUSSION}

This research presents a serious game that involves recognizing and imitating full-body movement, enabling individuals with ASC to use a crucial skill that would be relevant to achieve information about other people emotions. The bodily communication of emotions is of paramount importance for both typically and atypically developing individuals, including people with ASC.

In fact, Wilbarger et al. [76] demonstrated that information about emotional states are automatically processed 

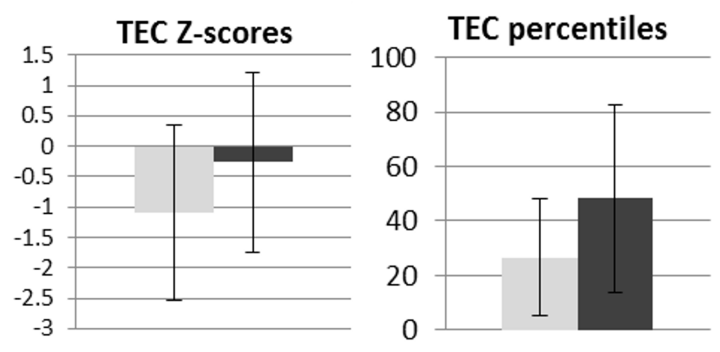

Pre-test $\square$ Post-test

Fig. 7. Pre-test (light grey) and post-test (dark-grey) percentiles mean scores for the children, the image show a general increment in children's scores

TABLE 5

Correlations between in-game scores and post-pre test TEC gains in raw TEC scores (top row), and centiles (bottom row).

\begin{tabular}{cccccc}
\hline \multicolumn{3}{c}{ Recognition Task } & \multicolumn{3}{c}{ Expression Task } \\
\hline Sessions & Sessions & Total & Sessions & Sessions & Total \\
$1-6$ & $7-10$ & & $1-6$ & $7-10$ & \\
\hline-0.26 & -0.04 & -0.22 & -0.21 & 0.47 & 0.41 \\
-0.27 & -0.23 & -0.43 & -0.40 & 0.71 & 0.64 \\
& & & & $(\mathrm{p}<0.05)$ & $(\mathrm{p}<0.05)$ \\
\hline
\end{tabular}

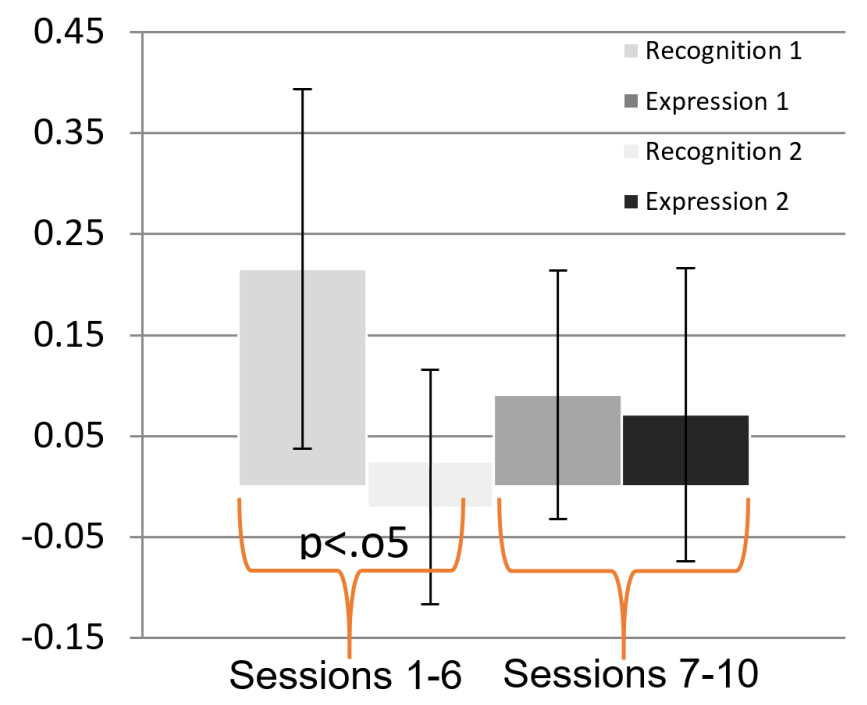

Fig. 8. Mean gains in recognition performances (light grey) and expression performances (dark grey) the recognition task rates grow mainly during the first six gaming sessions, while the expression recognition rates grow in the last four sessions.

when affective postures from ones own body match the affective postures of anothers body. Further, body postures may provide individuals with ASC a less aversive, more accessible means for transmitting social information than faces because they do not require eye contact [30]

This serious game proposed in a training program seems a promising tool to promote the ability to recognize and express emotions using body motions and gestures in children with ASC. An increasing of tasks accuracy from the beginning to the end of training sessions emerged in the
TABLE 6

Correct answers, TEC scores and centiles in the control group.

\begin{tabular}{ccccccc}
\hline & \multicolumn{3}{c}{ First assessment } & \multicolumn{2}{c}{ Second assessment } \\
\hline ID & $\begin{array}{c}\text { Correct } \\
\text { Answers }\end{array}$ & $\begin{array}{c}\text { TEC } \\
\text { pts }\end{array}$ & Centiles & $\begin{array}{c}\text { Correct } \\
\text { Answers }\end{array}$ & $\begin{array}{c}\text { TEC } \\
\text { pts }\end{array}$ & Centiles \\
\hline 21 & 17 & 8 & 46 & 17 & 8 & 46 \\
22 & 18 & 9 & 81 & 18 & 9 & 81 \\
23 & 14 & 6 & 10 & 15 & 7 & 23 \\
5 & 17 & 8 & 54 & 17 & 8 & 54 \\
6 & 17 & 8 & 46 & 18 & 49 & 81 \\
\hline Mean & 16.60 & 7.80 & 47.40 & 17.00 & 8.20 & 57.00
\end{tabular}

trained group. In particular, while the increase of recognition accuracy was concentrated in the first sessions of the game, the increase for expression accuracy is more gradual in all sessions. Moreover, the training seems to produce a transfer effect, as the children showed higher abilities to perform a standardized test (TEC) based on facial expression recognition. However, these results are obtained on a relatively small number of participants (10 children) with a specific age (8-10 years) and profile of functioning (high functioning). Further work is therefore needed to confirm the obtained results on larger groups and to extend the method to different ages and level of functioning.

\section{ACKNOWLEDGMENTS}

The research leading to these results has received funding from the European Communitys Seventh Framework Programme (FP7/2007-2013) under grant agreement No. 289021 (ASC-Inclusion).

\section{REFERENCES}

[1] D.-. A. P. Association et al., "Diagnostic and statistical manual of mental disorders," Arlington: American Psychiatric Publishing, 2013.

[2] L. Kanner et al., "Autistic disturbances of affective contact," Nervous child, vol. 2, no. 3, pp. 217-250, 1943.

[3] P. Hobson, "Understanding persons: The role of affect," 1993.

[4] C. Ashwin, E. Chapman, L. Colle, and S. Baron-Cohen, "Impaired recognition of negative basic emotions in autism: a test of the amygdala theory," Social neuroscience, vol. 1, no. 3-4, pp. 349-363, 2006.

[5] A. Klin, S. S. Sparrow, A. De Bildt, D. V. Cicchetti, D. J. Cohen, and F. R. Volkmar, "A normed study of face recognition in autism and related disorders," Journal of autism and developmental disorders, vol. 29, no. 6, pp. 499-508, 1999.

[6] K. M. Rump, J. L. Giovannelli, N. J. Minshew, and M. S. Strauss, "The development of emotion recognition in individuals with autism," Child development, vol. 80, no. 5, pp. 1434-1447, 2009.

[7] J. L. Tracy, R. W. Robins, R. A. Schriber, and M. Solomon, "Is emotion recognition impaired in individuals with autism spectrum disorders?" Journal of autism and developmental disorders, vol. 41, no. 1, pp. 102-109, 2011.

[8] S. J. Weeks and R. P. Hobson, "The salience of facial expression for autistic children," Journal of Child Psychology and Psychiatry, vol. 28, no. 1, pp. 137-152, 1987.

[9] G. Young-Browne, H. M. Rosenfeld, and F. D. Horowitz, "Infant discrimination of facial expressions," Child Development, pp. 555$562,1977$.

[10] N. H. Soken and A. D. Pick, "Intermodal perception of happy and angry expressive behaviors by seven-month-old infants," Child development, vol. 63, no. 4, pp. 787-795, 1992. 
[11] K. Durand, M. Gallay, A. Seigneuric, F. Robichon, and J.-Y. Baudouin, "The development of facial emotion recognition: The role of configural information," Journal of experimental child psychology, vol. 97, no. 1, pp. 14-27, 2007.

[12] C. J. Mondloch, S. Geldart, D. Maurer, and R. Le Grand, "Developmental changes in face processing skills," Journal of experimental child psychology, vol. 86, no. 1, pp. 67-84, 2003.

[13] C. M. Herba, S. Landau, T. Russell, C. Ecker, and M. L. Phillips, "The development of emotion-processing in children: effects of age, emotion, and intensity," Journal of Child Psychology and Psychiatry, vol. 47, no. 11, pp. 1098-1106, 2006.

[14] L. A. Thomas, M. D. De Bellis, R. Graham, and K. S. LaBar, "Development of emotional facial recognition in late childhood and adolescence," Developmental science, vol. 10, no. 5, pp. 547-558, 2007.

[15] S. Begeer, H. M. Koot, C. Rieffe, M. M. Terwogt, and H. Stegge, "Emotional competence in children with autism: Diagnostic criteria and empirical evidence," Developmental Review, vol. 28, no. 3, pp. 342-369, 2008.

[16] H. J. Nuske, G. Vivanti, and C. Dissanayake, "Are emotion impairments unique to, universal, or specific in autism spectrum disorder? a comprehensive review," Cognition E Emotion, vol. 27, no. 6, pp. 1042-1061, 2013.

[17] M. Uljarevic and A. Hamilton, "Recognition of emotions in autism: a formal meta-analysis," Journal of autism and developmental disorders, vol. 43, no. 7, pp. 1517-1526, 2013.

[18] C. C. Peterson, V. Slaughter, and C. Brownell, "Children with autism spectrum disorder are skilled at reading emotion body language," Journal of experimental child psychology, vol. 139, pp. 3550, 2015.

[19] B. De Gelder, "Why bodies? twelve reasons for including bodily expressions in affective neuroscience," Philosophical Transactions of the Royal Society of London B: Biological Sciences, vol. 364, no. 1535, pp. 3475-3484, 2009.

[20] B. De Gelder, R. Hortensius, and M. Tamietto, "Attention and awareness each influence amygdala activity for dynamic bodily expressions? a short review," Frontiers in integrative neuroscience, vol. 6, 2012.

[21] B. de Gelder and R. Hortensius, "The many faces of the emotional body," in New frontiers in social neuroscience. Springer, 2014, pp. 153-164.

[22] B. App, D. N. McIntosh, C. L. Reed, and M. J. Hertenstein, "Nonverbal channel use in communication of emotion: how may depend on why." Emotion, vol. 11, no. 3, p. 603, 2011.

[23] A. P. Atkinson, W. H. Dittrich, A. J. Gemmell, A. W. Young et al., "Emotion perception from dynamic and static body expressions in point-light and full-light displays," PERCEPTION-LONDON-, vol. 33, pp. 717-746, 2004.

[24] B. De Gelder, "Towards the neurobiology of emotional body language," Nature Reviews Neuroscience, vol. 7, no. 3, pp. 242-249, 2006.

[25] B. De Gelder and J. Van den Stock, "The bodily expressive action stimulus test (beast). construction and validation of a stimulus basis for measuring perception of whole body expression of emotions," Frontiers in psychology, vol. 2, 2011.

[26] F. E. Pollick, V. Lestou, J. Ryu, and S.-B. Cho, "Estimating the efficiency of recognizing gender and affect from biological motion," Vision research, vol. 42, no. 20, pp. 2345-2355, 2002.

[27] T. J. Clarke, M. F. Bradshaw, D. T. Field, S. E. Hampson, and D. Rose, "The perception of emotion from body movement in point-light displays of interpersonal dialogue," Perception, vol. 34, no. 10, pp. 1171-1180, 2005.

[28] K. Schindler, L. Van Gool, and B. de Gelder, "Recognizing emotions expressed by body pose: A biologically inspired neural model," Neural networks, vol. 21, no. 9, pp. 1238-1246, 2008.

[29] J. W. Tanaka and A. Sung, "The eye avoidance hypothesis of autism face processing," Journal of autism and developmental disorders, vol. 46, no. 5, pp. 1538-1552, 2016.

[30] C. L. Reed, P. M. Beall, V. E. Stone, L. Kopelioff, D. J. Pulham, and S. L. Hepburn, "Brief report: Perception of body posture? what individuals with autism spectrum disorder might be missing," Journal of autism and developmental disorders, vol. 37, no. 8, pp. 15761584, 2007.

[31] S. Piana, A. Staglian, A. Camurri, and F. Odone, "A set of fullbody movement features for emotion recognition to help children affected by autism spectrum condition," in IDGEI International Workshop. IDGEI International Workshop, 2013.
[32] S. Piana, A. Staglian, F. Odone, A. Verri, and A. Camurri, "Realtime automatic emotion recognition from body," in IDGEI International Workshop. IDGEI International Workshop, 2014, to appear in IDGEI 2014 proceedings.

[33] S. Piana, A. Staglianò, F. Odone, and A. Camurri, "Adaptive body gesture representation for automatic emotion recognition," ACM Transactions on Interactive Intelligent Systems (TiiS), vol. 6, no. 1, p. 6, 2016.

[34] R. T. Boone and J. G. Cunningham, "Children's decoding of emotion in expressive body movement: The development of cue attunement," Developmental psychology, vol. 34, pp. 1007-1016, 1998.

[35] A. Camurri, I. Lagerlöf, and G. Volpe, "Recognizing emotion from dance movement: comparison of spectator recognition and automated techniques," International journal of human-computer studies, vol. 59, no. 1, pp. 213-225, 2003.

[36] D. Glowinski, N. Dael, A. Camurri, G. Volpe, M. Mortillaro, and K. Scherer, "Toward a minimal representation of affective gestures," Affective Computing, IEEE Transactions on, vol. 2, no. 2, pp. 106-118, 2011.

[37] A. Kapur, A. Kapur, N. Virii-Babul, G. Tzanetakis, and P. F. Driessen, Gesture-based affective computing on motion capture data. Springer, 2005, pp. 1-7.

[38] F. Pons, P. L. Harris, and M. de Rosnay, "Emotion comprehension between 3 and 11 years: Developmental periods and hierarchical organization," European journal of developmental psychology, vol. 1, no. 2, pp. 127-152, 2004.

[39] R. Laban and F. C. Lawrence, Effort. Macdonald \& Evans, 1947.

[40] R. von Laban, Modern educational dance. Princeton Book Co Pub, 1975.

[41] S. Ramdoss, W. Machalicek, M. Rispoli, A. Mulloy, R. Lang, and M. O'Reilly, "Computer-based interventions to improve social and emotional skills in individuals with autism spectrum disorders: A systematic review," Developmental neurorehabilitation, vol. 15, no. 2, pp. 119-135, 2012.

[42] T. Balomenos, A. Raouzaiou, S. Ioannou, A. Drosopoulos, K. Karpouzis, and S. Kollias, Emotion analysis in man-machine interaction systems. Springer, 2005, pp. 318-328.

[43] E. Barakova, G. Van Wanrooij, R. Van Limpt, and M. Menting, “Using an emergent system concept in designing interactive games for autistic children," in Proceedings of the 6th international conference on Interaction design and children. ACM, 2007, pp. 73-76.

[44] A. Battocchi, F. Pianesi, P. Venuti, A. Ben-Sasson, E. Gal, and P. L. Weiss, "Collaborative puzzle game: Fostering collaboration in children with autistic spectrum disorder (asd) and with typical development," in Virtual Rehabilitation International Conference, 2009. IEEE, 2009, pp. 204-204.

[45] J. P. Hourcade, N. E. Bullock-Rest, and T. E. Hansen, "Multitouch tablet applications and activities to enhance the social skills of children with autism spectrum disorders," Personal and ubiquitous computing, vol. 16, no. 2, pp. 157-168, 2012.

[46] M. E. Hoque, J. K. Lane, R. El Kaliouby, M. Goodwin, and R. W. Picard, "Exploring speech therapy games with children on the autism spectrum," 2009.

[47] M. A. Sharmin, M. M. Rahman, S. I. Ahmed, M. M. Rahman, and S. Ferdous, "Teaching intelligible speech to the autistic children by interactive computer games," in Proceedings of the 2011 ACM Symposium on Applied Computing. ACM, 2011, pp. 1208-1209.

[48] C. S. Lányi and Á. Tilinger, "Multimedia and virtual reality in the rehabilitation of autistic children," in International Conference on Computers for Handicapped Persons. Springer, 2004, pp. 22-28.

[49] N. Parés, A. Carreras, J. Durany, J. Ferrer, P. Freixa, D. Gómez, O. Kruglanski, R. Parés, J. I. Ribas, M. Soler et al., "Promotion of creative activity in children with severe autism through visuals in an interactive multisensory environment," in Proceedings of the 2005 conference on Interaction design and children. ACM, 2005, pp. 110-116.

[50] S. Bereznak, K. M. Ayres, L. C. Mechling, and J. L. Alexander, "Video self-prompting and mobile technology to increase daily living and vocational independence for students with autism spectrum disorders," Journal of Developmental and Physical Disabilities, vol. 24, no. 3, pp. 269-285, 2012.

[51] T.-W. Tsai and M.-Y. Lin, "An application of interactive game for facial expression of the autisms," in International Conference on Technologies for E-Learning and Digital Entertainment. Springer, 2011, pp. 204-211. 
[52] S. Jain, B. Tamersoy, Y. Zhang, J. K. Aggarwal, and V. Orvalho, “An interactive game for teaching facial expressions to children with autism spectrum disorders," in 2012 5th International Symposium on Communications, Control and Signal Processing. IEEE, 2012, pp. $1-4$.

[53] B. Robins, K. Dautenhahn, R. Te Boekhorst, and A. Billard, "Robotic assistants in therapy and education of children with autism: can a small humanoid robot help encourage social interaction skills?" Universal Access in the Information Society, vol. 4, no. 2, pp. 105-120, 2005.

[54] J. Wainer, B. Robins, F. Amirabdollahian, and K. Dautenhahn, "Using the humanoid robot kaspar to autonomously play triadic games and facilitate collaborative play among children with autism," IEEE Transactions on Autonomous Mental Development, vol. 6, no. 3, pp. 183-199, 2014.

[55] K. Dautenhahn and A. Billard, "Games children with autism can play with robota, a humanoid robotic doll," in Universal access and assistive technology. Springer, 2002, pp. 179-190.

[56] L. Cruz, D. Lucio, and L. Velho, "Kinect and rgbd images: Challenges and applications," in 2012 25th SIBGRAPI Conference on Graphics, Patterns and Images Tutorials. IEEE, 2012, pp. 36-49.

[57] B. Schuller, E. Marchi, S. Baron-Cohen, H. O'Reilly, P. Robinson, I. Davies, O. Golan, S. Friedenson, S. Tal, S. Newman et al., "Asc-inclusion: Interactive emotion games for social inclusion of children with autism spectrum conditions," in Proceedings 1st International Workshop on Intelligent Digital Games for Empowerment and Inclusion (IDGEI 2013) held in conjunction with the 8th Foundations of Digital Games, 2013.

[58] E. Marchi, B. Schuller, A. Baird, S. Baron-Cohen, A. Lassalle, H. OReilly, D. Pigat, P. Robinson, I. Davies, T. Baltrušaitis et al., "The asc-inclusion perceptual serious gaming platform for autistic children," IEEE Transactions on Games, 2018.

[59] P. Ekman, "Differential communication of affect by head and body cues." Journal of personality and social psychology, vol. 2, no. 5, p. 726, 1965.

[60] A. Camurri, B. Mazzarino, M. Ricchetti, R. Timmers, and G. Volpe, "Multimodal analysis of expressive gesture in music and dance performances," in Gesture-based communication in human-computer interaction. Springer, 2004, pp. 20-39.

[61] A. Camurri, G. Volpe, S. Piana, M. Mancini, R. Niewiadomski, N. Ferrari, and C. Canepa, "The dancer in the eye: towards a multilayered computational framework of qualities in movement," in Proceedings of the 3rd International Symposium on Movement and Computing. ACM, 2016, p. 6.

[62] S. Piana, P. Alborno, R. Niewiadomski, M. Mancini, G. Volpe, and A. Camurri, "Movement fluidity analysis based on performance and perception," in Proceedings of the 2016 CHI Conference Extended Abstracts on Human Factors in Computing Systems, ser. CHI EA '16. New York, NY, USA: ACM, 2016, pp. 1629-1636. [Online]. Available: http://doi.acm.org/10.1145/2851581.2892478

[63] A. Camurri, S. Hashimoto, M. Ricchetti, A. Ricci, K. Suzuki, R. Trocca, and G. Volpe, "Eyesweb: Toward gesture and affect recognition in interactive dance and music systems," Computer Music Journal, vol. 24, no. 1, pp. 57-69, 2000.

[64] A. Camurri, B. Mazzarino, and G. Volpe, "Analysis of expressive gesture: The eyesweb expressive gesture processing library," in International Gesture Workshop. Springer, 2003, pp. 460-467.

[65] A. Camurri, P. Coletta, A. Massari, B. Mazzarino, M. Peri, M. Ricchetti, A. Ricci, and G. Volpe, "Toward real-time multimodal processing: Eyesweb 4.0," in Proceedings of the artificial intelligence and the simulation of behaviour (AISB), 2004 convention: motion. Emotion and cognition. Citeseer, 2004, pp. 22-26.

[66] C. Basso, M. Santoro, A. Verri, and S. Villa, "Paddle: proximal algorithm for dual dictionaries learning," Artificial Neural Networks and Machine Learning-ICANN 2011, pp. 379-386, 2011.

[67] "Istituto Chiossone," http://www.chiossone.it/, 2017.

[68] “http://centromaisoli.it/," http://centromaisoli.it/, 2017.

[69] "Philos," http://www.associazionephilos.net/, 2017.

[70] G. H. Roid, L. J. Miller, and C. Koch, Leiter international performance scale. Stoelting, 2013.

[71] L. B. Jahromi, S. E. Meek, and S. Ober-Reynolds, "Emotion regulation in the context of frustration in children with high functioning autism and their typical peers," Journal of Child Psychology and Psychiatry, vol. 53, no. 12, pp. 1250-1258, 2012.

[72] J. Legiša, D. S. Messinger, E. Kermol, and L. Marlier, “Emotional responses to odors in children with high-functioning autism: au- tonomic arousal, facial behavior and self-report," Journal of autism and developmental disorders, vol. 43, no. 4, pp. 869-879, 2013.

[73] L. A. Edwards, "A meta-analysis of imitation abilities in individuals with autism spectrum disorders," Autism Research, vol. 7, no. 3, pp. 363-380, 2014.

[74] J. Cohen, "Statistical power analysis for the behavioral sciences (revised ed.)," 1977.

[75] C. Spearman, "Correlation calculated from faulty data," British journal of psychology, vol. 3, no. 3, pp. 271-295, 1910.

[76] J. L. Wilbarger, C. L. Reed, and D. N. McIntosh, "Implicit influence of affective postures on the perception of others: You can't show me how i feel." Emotion, vol. 11, no. 3, p. 481, 2011.

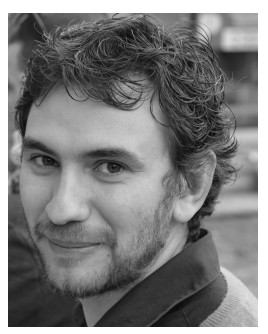

Stefano Piana received his doctoral degree in Electronic and Computer Engineering, Robotics and Telecommunications for his study on $\mathrm{Au}$ tomatic Emotion Recognition from body gestures in 2016 from the University of Genoa in Genoa/ltaly. He is currently working as a postdoc researcher in the CasaPaganini - InfoMus Research Centre at the DIBRIS department of University Of Genoa in Genoa, Italy. His research focuses on affective computing, human body movement analysis, emotion recognition. $\mathrm{He}$ has been and is currently involved in various EU-FP7 and H2020. $\mathrm{He}$ (co-)authored several publications in peer-reviewed journals and conference proceedings.

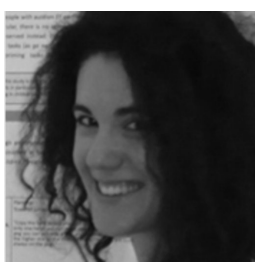

Chiara Malagoli received her M.Sc. degree in Psychology in 2011 and her doctoral degree in 2015 for her study on control processes and Emotion Regulation in Adolescence from the University of Genoa in Genoa/ltaly. She is currently working as a post-doc research fellow at Department of Education and Psychology (SCIFOPSI), University of Florence. She (co)authored several publications in peer-reviewed journals and conference proceedings.

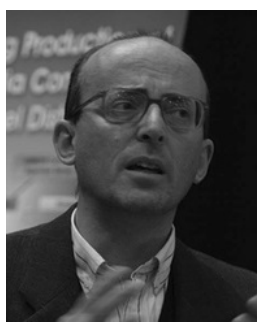

Antonio Camurri is full professor at DIBRIS University of Genoa. His research interests include multimodal interfaces, computational models of non-verbal expressive gesture, non-verbal social behavior, sound and music computing, multimodal interactive systems for theatre, music, dance, museums, and for therapy and rehabilitation. Founder of InfoMus Lab and of Casa Paganini - InfoMus Research Centre of University of Genoa, he coordinates and is local project manager of several European Projects in FP5 IST, FP6, CRAFT, FP7 ICT, Culture 2007. He is (co-)author of more than 200 scientific publications in peer reviewed international conferences and journals. 


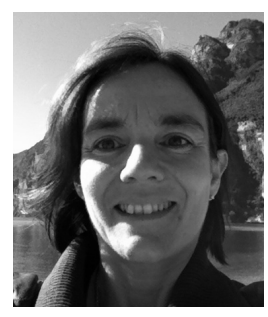

Maria Carmen Usai is associate professor of Developmental and Educational Psychology at the Department of Education, University of Genoa. Her current research interests include the control processes in typical and atypical human development 